\title{
FARMACODERMIAS BOLHOSAS GRAVES
}

\section{Pôster}

Autores deste trabalho:

Chayanne Andrade de Araujo: Hospital Infantil Sabará / Instituto PENSI

Alessandra Miramontes Lima: Hospital Infantil Sabará / Instituto PENSI

Ligia Spagnol Ranalli: Hospital Infantil Sabará / Instituto PENSI

Marilise Guedes Candido lando: Hospital Infantil Sabará / Instituto PENSI

Fátima Rodrigues Fernandes: Hospital Infantil Sabará / Instituto PENSI

Carolina Gonçalves Contin: Hospital Infantil Sabará

Karen Chicol Gonçalves: Hospital Infantil Sabará

Área do Trabalho: Pediatria

Data da submissão:09/08/2018 às 14:29

\section{Justificativa}

Síndrome de Stevens-Johnson (SSJ) e Necrólise Epidérmica Tóxica (NET), são reações cutâneas de hipersensibilidade tardia, associadas a drogas e infeç̧ões, graves e cuja mortalidade pode chegar a $19,4 \%$. A etiopatogenia e tratamento são pouco conhecidos e controversos.

\section{Objetivo(s)}

Relato de casos e desfechos de farmacodermias graves bolhosas acompanhadas em Hospital Pediátrico Terciário.

\section{Método(s)}

Estudo retrospectivo, descritivo e unicêntrico dos casos de SSJ e NET, no período de 2012 a 2018, através de revisão de prontuários eletrônicos e registro fotográfico de lesões cutâneas.

\section{Resultado(s)}

Acompanhados 5 casos ( 3 casos de SSJ, um caso de SSJ/NET e um caso de NET), idade média ao diagnóstico de 5,8 anos, predominância feminina (4:1) e tempo médio de internação de 27 dias. As drogas implicadas foram: anticonvulsivantes (2 casos), derivados imidazólicos (1 caso), betalactâmico e dipirona (1 caso); 2 casos tinham sorologia positiva (IgM) para Mycoplasma pneumoniae, que foi a causa provável em um dos casos, onde não houve histórico de fármaco envolvido. Todos foram tratados em unidade de terapia intensiva, com seguimento de equipe multidisciplinar, monitorização de acometimento sistêmico, cobertura antibiótica e cuidados com a pele. Quatro casos receberam Imunoglobulina humana, $1 \mathrm{~g} / \mathrm{kg}$, por uma média de 3,5 dias. Um paciente fez tratamento concomitante com Ciclosporina $3 \mathrm{mg} / \mathrm{kg}$ por 8 dias. Um caso, atribuído a infecção por Mycoplasma tratou apenas com corticóide e antibiótico. Biópsia cutânea foi realizada em um paciente. Todos os casos evoluíram com remissão, sem maiores sequelas.

\section{Conclusão (ões)}


As farmacodermias graves representam uma emergência médica, cujo reconhecimento precoce e manejo apropriado são decisivos para otimizar a sobrevida. A Imunoglobulina humana foi o tratamento de escolha para os casos conduzidos, se mostrando segura e eficaz. Nenhum caso evoluiu com complicações sistêmicas ou óbito. Destacamos a importância da diagnóstico precoce e avaliação criteriosa dos fatores causais prováveis. 